\title{
Diversity of cyanobacteria in shipwrecks in the shallow water of New Calabar River, Nigeria
}

\begin{abstract}
The diversity of shipwrecks cyanobacteria in shallow water of New Calabar River, in River State - Nigeria was examined. Bio-concretions from three shipwrecks located at the estuary of New Calabar River were collected and the visual examination of the bioconcretions revealed 3 types of rusticles: Brown rusticles (braided structures attached on the wreck surfaces), Dendritic concretion (layered coatings of different concretions) and Biofilm (slimy coatings). The 16S rRNA gene sequences from the rusticles was performed by Next Generation Sequencing Technique to determine the nucleotide sequence of cyanobacteria present in the rusticle samples using automated Illumina Miseq analyser. The results revealed a diversity of cyanobacteria in the rusticle samples. The cyanobacteria composition showed different species of diazotrophic filamentous genus Trichodesmium., it dominated the bio-concretion, having in abundance 4 of its species; T. erythraeum $(8.75 \%)$, T. hildebrandtii $(1.08 \%)$, T. contortum $(1.04 \%)$ and T. tenue $(1.02 \%)$. The availability of iron on the bio-concretions could explain the reason for the presence of the Trichodesmium clades present. Phormidiaceae, cyanobacteriacea, we can associate the formation of rusticles by cyanobacteria as one of their eroding characteristics on shipwrecks. This study attempts to validate the role of mat-matrix forming cyanobacteria in aerobic corrosion in shallow water shipwrecks.
\end{abstract}

Keywords: shipwrecks, rusticles, cyanobacteria, illumina, Trichodesmium
Volume 8 Issue 5 - 2020

\author{
Daokoru-Olukole CG,' Okpokwasili GSC² \\ 'Department of Microbiology, Niger Delta University, Nigeria \\ ${ }^{2}$ Department of Microbiology, University of Port Harcourt, \\ Nigeria
}

\begin{abstract}
Correspondence: Daokoru-Olukole CG, Department of Microbiology, Niger Delta University, P.M.B 07I Wilberforce Island, Yenagoa, Nigeria, Tel +2347038730020 ,
\end{abstract} Email dkchima@gmail.com

Received: October 16, 2020 | Published: October 30, 2020

\section{Introduction}

Cyanobacteria are a group of microorganisms that can perform oxygenic photosynthesis with the ability of fixing atmospheric nitrogen and, carbon. ${ }^{1}$ There about 15 genera of cyanobacteria with more than 2000 species with remarkable diversity in their morphology. Cyanobacteria are unicellular, with species growing as colonies or filaments. These are large enough to be visible to the naked eye. ${ }^{2}$ Being ubiquitous in nature explains the existence of cyanobacteria in diverse habitat ranging from freshwater, soil, biological soil, crust, and rocks. These prokaryotes can tolerate extreme conditions such as hot springs, hypersaline water, freezing environments, and deserts. ${ }^{3}$ Even in extremely stressed conditions such as volcanic ash and anthropogenically disturbed areas, ${ }^{1}$ a minimum requirement of light, Carbon dioxide and water, ${ }^{4}$ a temperature range of $45^{\circ} \mathrm{C}-75^{\circ} \mathrm{C}$ have been reported. With these remarkable adaptabilities of Cyanobacteria to different environmental conditions, they are reported to inhabit extremely lithic habitats such as rocks and walls of monuments and buildings. ${ }^{5}$ The lithobionic cyanobacteria cause an unacceptable discolouration and bio-deterioration of coloured surfaces of walls of monuments and buildings.

Cyanobacteria have also been reported on natural reefs. ${ }^{6}$ Wagner $^{7}$ hypothesized the presence of cyanobacteria on artificial reef such as shipwreck and a relationship between cyanobacteria and other organisms around the shipwreck have been reported. He posited that life especially corals in direct contact with shipwreck will have to contend with invading cyanobacteria that colonize the damaged reef. When a ship goes aground, cyanobacteria which are primary colonizers or pioneer microorganisms of lithic, substrates begin to colonize and in turn promote the growth of other heterotrophic bacteria. Ship grounding can have significant adverse effects on life in water, especially, coral reefs. Shipwreck's physical impact in the marine environment can change species composition and competitive dynamics within the benthic assemblages. ${ }^{8}$ Marshall and Edgar (2003) reported the potential risk of a shipwreck introducing a nonnative species that may subsequently colonize the natural reef. It is remarkable to note that the presence of a wreck alters the water chemistry as the ship continues to rust away. During the course of time, the change in water chemistry can promote the colonization of certain species of benthic organism especially species whose growth is fascinated by the leached iron from the wreck.

In a marine environment (ocean) primary production is limited by the low concentration of iron $(0.1-1 \mathrm{~nm}),{ }^{9}$ although, this is not the case in Niger Delta region where iron concentration is naturally high. And as such the competition for the bio-available iron is high. Cyanobacteria a pioneer colonizer of shipwreck usually is in high demand of iron due to its involvement in the function of a variety of crucial enzymes. Despite the deleterious effects of shipwreck on the water body, cyanobacteria with their siderophores are adapted to scavenging and solubilizing iron from shipwrecks. To this effect, researchers had hypothesized that there would be bio-available iron in the vicinity of shipwrecks that encourages the growth of cyanobacteria. In a certain extreme environment like salt marshes, cyanobacteria play a key ecological role in binding sediments by forming densely layered mats and these mats are referred to as stromatrolites. ${ }^{2}$ 


\section{Materials and methods}

\section{General description of the study site}

Three different shipwrecks situated at Rumuolumeni axis, popularly known as Iwofe Jetty along the New Calabar River in Rivers State were used for this research. As at the time of study only one of the wrecks still had its name visible on the wreck hull, -the Endurance Shipwreck. The names of the other two had been eaten off by rust, and are considered for the purpose of this work as
Unknown shipwreck I and Unknown shipwreck II. All the wrecks differ in regards to orientation and position on the bottom, therefore, the exposures of the wrecks to sunlight and water circulations varies, The Unknown shipwreck I is almost buried in the sediments with a few of the hull iron protruding upwards. Endurance Shipwreck rests upright with half the hull submerged and the unknown Shipwreck II rest horizontally at the bottom. The criterion for choosing each wreck is having been sunken for over 20 years; the exact time of wreck is unknown. The study site is brackish water and is predominantly mangrove, comprising mud flat when the tide is low (Figure $1 \& 2$ ).

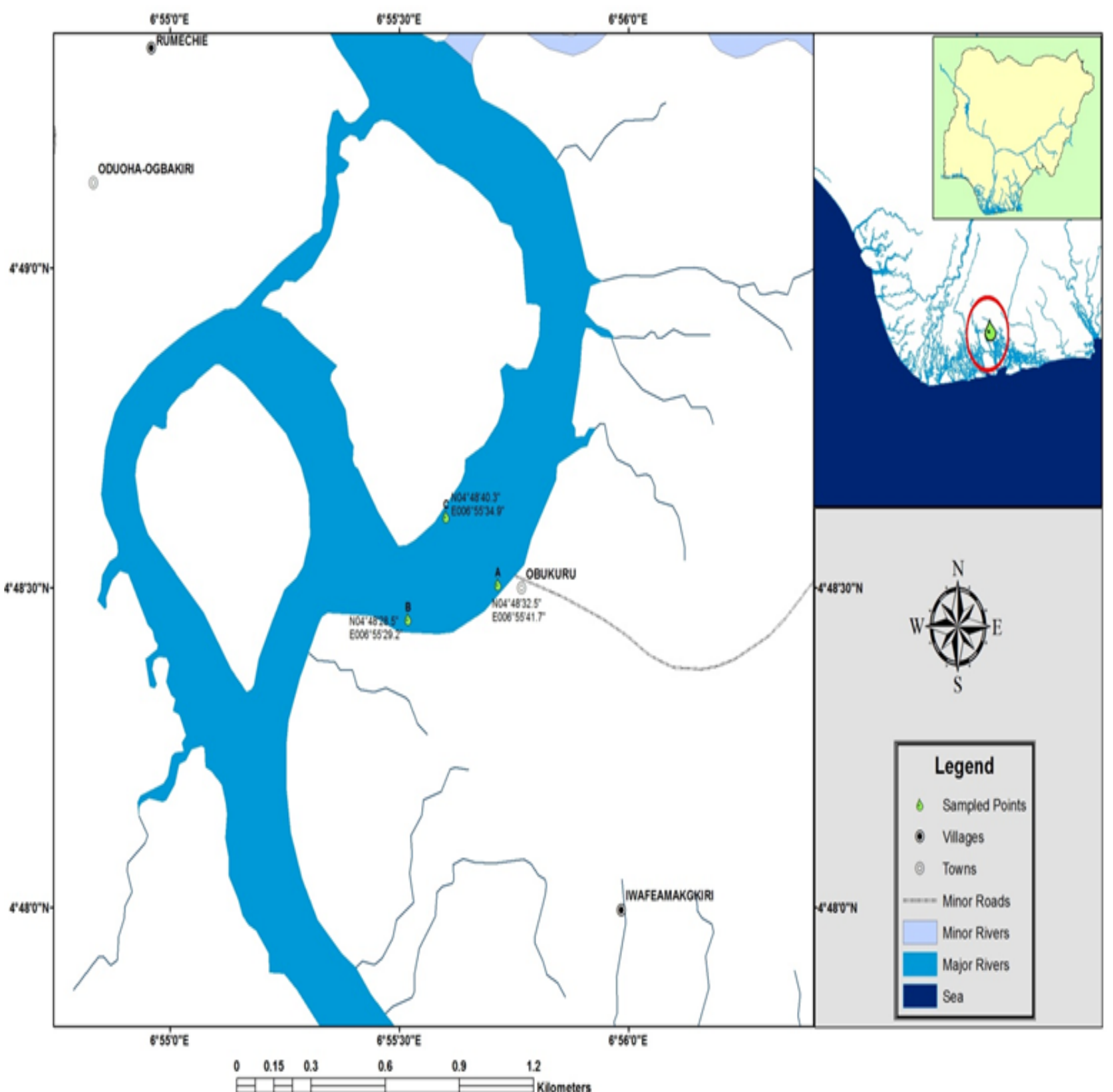

Figure I Study area location in New Calabar River. 


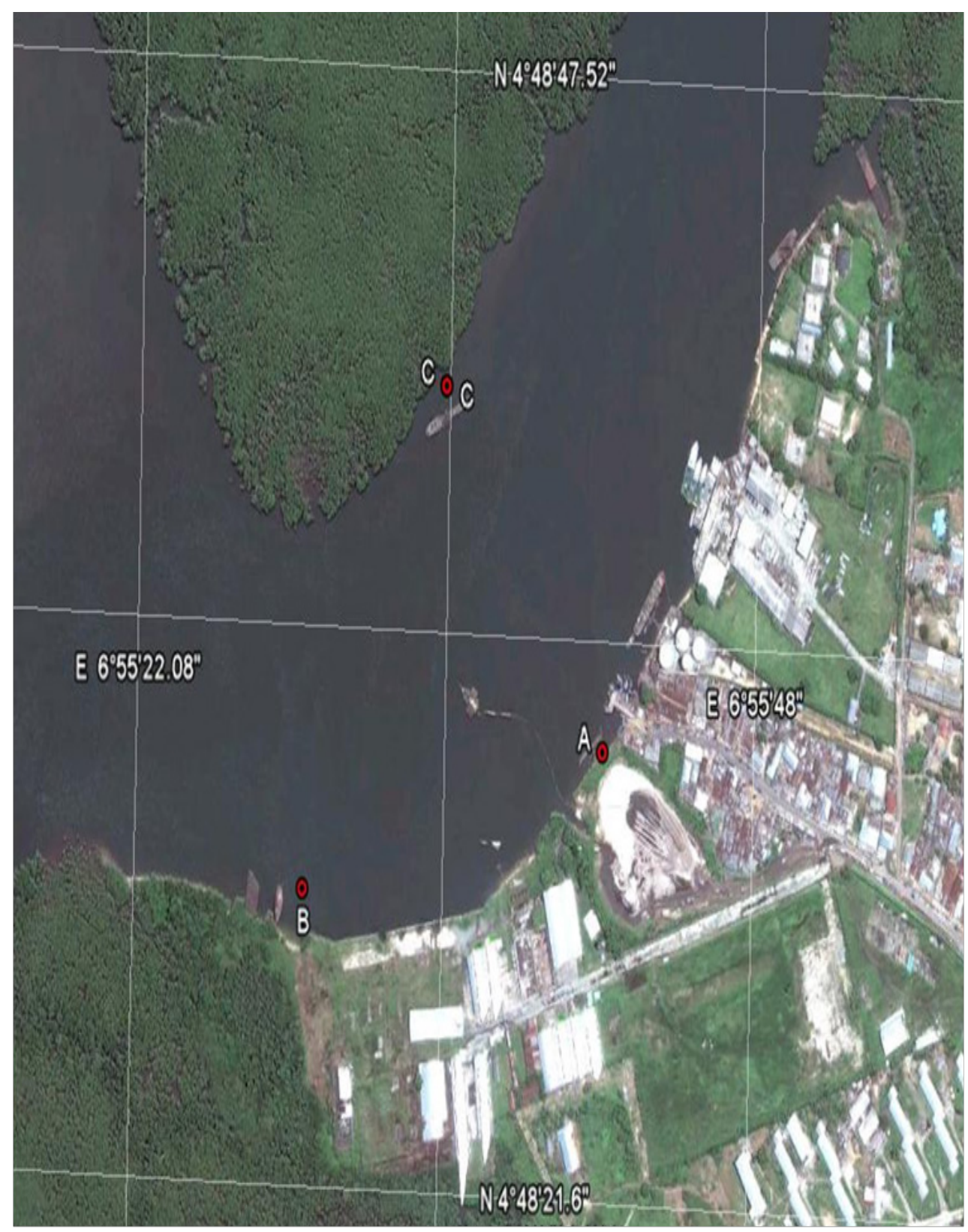

Figure 2 Study locations plotted on Google Earth image Scale I:100 000.

- $\quad$ OSampled points

Key

Point A, unknown ship designated as SH-D;

Point B, Endurance Vessel designated as $\mathrm{SH}-\mathrm{E}$;

Point C, Unknown ship designated as SH-F.

\section{Collection and study of biological samples (rusticles)}

The study of rusticles was done by direct sampling followed by DNA analysis. The documentation of the microbiological communities (rusticles) growing on the wrecks was conducted. The colour and texture of rusticles were assessed. All rusticle samples were collected in sterile polythene bags and were placed in a sample cooler and carried to the laboratory where they were analysed.

\section{Molecular microbial diversity study}

\section{DNA extraction}

Total genomic DNA was extracted from rusticles sample using Zymo Soil Microbe DNA extraction Kit according to the manufactures. $0.25 \mathrm{~g}$ of rusticles sample was added into a ZR bashing bead $^{\mathrm{TM}}$ lysis tube followed by the addition of $750 \mu 1$ lysis solution to the tube. The content in the ZR bashing bead ${ }^{\mathrm{TM}}$ was secured in a bead 
beater fitted with a $2 \mathrm{ml}$ tube holder and was disrupted in a vortex mixer at maximum speed for 5 minutes. The ZR bashing bead ${ }^{\mathrm{TM}}$ lysis tube was Centrifuge in a micro centrifuge at $10,000 \mathrm{x} g$ for 1 minute. $400 \mu 1$ of the filtrate was added to a Zymo-Spin ${ }^{\mathrm{TM}}$ IV spin filter in a collection tube and centrifuge at 7,000 $\mathrm{rmp}(\sim 7,000 \mathrm{x} g)$ for 1 minutes.

This was followed by the addition of $1,200 \mu 1$ of soil DNA Binding Buffer to the filtrate in the Collection Tube. $800 \mu$ of the mixture from above was added to a Zymo-Spin ${ }^{\mathrm{TM}}$ IIC column in a collection tube and centrifuge at $10,000 \times g$ for 1 minute. The flow through from the collection tube was discarded and this particular step was repeated with the remaining filtrate. $200 \mu \mathrm{l}$ of DNA pre-wash buffer was thereafter added to the Zymo-Spin ${ }^{\mathrm{TM}}$ IIC column in a new collection tube and centrifuge at $10,000 \times \mathrm{g}$ for 1 minute after which 500 soil DNA wash buffer was added to the Zymo-Spin ${ }^{\mathrm{TM}}$ IIC column and centrifuge at $10,000 \times \mathrm{g}$ for 1 minute. The Zymo-Spin ${ }^{\mathrm{TM}}$ IIC column was transferred into a clean $1.5 \mathrm{ml}$ micro centrifuge tube and $100 \mu \mathrm{l}$ DNA elution buffer was added directly to the column matrix. This was centrifuge $10,000 \times g$ for 30 seconds to elude the DNA. The eluted DNA was transferred to a Zymo-spin ${ }^{\mathrm{TM}}$ IV-HRC spin filter in a clean 1.5 microcentrifuge tube and centrifuge at $8000 \mathrm{x}$ g for 1 minute. The filtered DNA is now suitable for PCR applications.

\section{DNA amplification by polymerase chain reaction (PCR)}

PCR amplifications were performed, although not with a cyanobacteria specific primer. A standard $50 \mu \mathrm{l}$ PCR reaction solution contained $25 \mu \mathrm{l}$ Dream Taq Master Mix, $1 \mu \mathrm{M}$ of each primer, and $10 \mu l$ of metagenomic DNA as the template. Amplification of a part of the 16S rRNA gene was done using a universal bacteria primer $27 \mathrm{~F}$ with adapter and $518 \mathrm{R}$ with adapter, this was to determine both the cyanobacteria and other classes of bacteria present in the environmental samples. After an initial heating step at $95^{\circ} \mathrm{C}$ for $3 \mathrm{~min}$, a total of 35 PCR cycles were run under the following conditions: denaturation at $95^{\circ} \mathrm{C}$ for $30 \mathrm{~s}$, annealing temperature at $52^{\circ} \mathrm{C}$ for $30 \mathrm{~s}$ and extension $72^{\circ} \mathrm{C}$ for $1 \mathrm{~min} 30 \mathrm{~s}$ and a final extension at $72^{\circ} \mathrm{C}$ for $10 \mathrm{~min}$. The primer pair used (forward primer, 27F); reverse primer, 518R, with adapter (Baker et al., 2003). Amplified products were detected on $1 \%$ agarose gels electrophoresed in $1 \times$ TBE buffer, stained with ethidium bromide and photographed on an UV trans-illuminator.

\section{DNA sequencing}

\section{S rRNA gene amplification and Illumina Miseq sequencing}

An aliquot $(50 \mathrm{ng})$ of purified DNA from each sample were used as template for amplification. The V1 and V3 hyper variable regions of bacterial 16S rRNAs (Escherichia coli positions 27-518) were amplified using a unique 7-bp barcode sequence contained the Illumina Miseq sequencing adapter at the 5 'end of each primer, respectively. The targeted gene region has been shown to be the most appropriate for the accurate phylogenetic reconstruction of bacteria (Biddle et al., 2008).

\section{Processing of Illumina Miseq data}

Metagenomics analysis was done by MiSeq Reporter, inbuilt software on Illumina' Miseq platform was used for the 16S metagenomics analysis. The version of the software used is Analysis software version: 2.4.60.8.

\section{Results}

The physical examination of bio-concretions collected from the shipwrecks revealed 3 types of rusticles: Brown rusticles (braided structures attached on the wreck surfaces), Dendritic concretion (layered coatings of different concretions) and Biofilm (slimy coatings). The colour of rusticles observed on our site had a shade of brown through white with sparingly orange on it. We also notice a black colour inside the rusticles. The term rusticle is used as a collective name to describe the bio-sconcretions. ${ }^{8}$

The relationship of elements within the bio-concretious structure with dominant atom first is;

$$
\begin{aligned}
& \text { SH-RD: } \mathrm{Fe}>\mathrm{Ca}>\mathrm{Mn}>\mathrm{Mg} \\
& \text { SH-RE: } \mathrm{Fe}>\mathrm{Ca}>\mathrm{Mn}>\mathrm{Mg} \\
& \text { SH-RF: } \mathrm{Fe}>\mathrm{Ca}>\mathrm{Mn}>\mathrm{Mg}
\end{aligned}
$$

The concentration of the metal found on the bio-concretions of the three shipwrecks followed the same pattern. Fe was the dominant metal and was as high as $9250 \mathrm{mg} / \mathrm{kg}$. On the three wrecks the Fe content obtained was very high, $8950 \mathrm{mg} / \mathrm{kg}, 9250 \mathrm{mg} / \mathrm{kg} \& 9050 \mathrm{mg} /$ $\mathrm{kg}$ respectively. The high concentration of iron on the rusticles is likely due to bio-extraction of iron from the steel of shipwreck which aggravates the weakening of the steel and this suggest that with time there will be a complete collapse of the frame of the ship. Calcium content was high on the rusticles observed on the wrecks. Cullimore $\&$ Johnston ${ }^{10}$ reported low calcium content on rusticles collected from Titanic. There is considerable variation in the elemental composition of the rusticles tested; however, this reflects the heterogeneous nature of the structures themselves. This is also consistent with Cullimore \& Johnston. ${ }^{10}$ When the Fe content is high on the rusticles it is said to be more of complex ferric oxides and hydroxides. ${ }^{10}$

The result of the 16SrDNA obtained from the rusticle samples revealed the presence of cyanobacteria from the phylum-level down to the species-level in the shipwreck's samples investigated. The percentage total reads of cyanobacteria in the three shipwrecks are $34.72 \%, 21 \%$ and $24.07 \%$ for SH-RD, SH-RE and SH-RF respectively. The Oscillatoriophycideae $(32.7 \%)$ is the only class of cyanobacteria found in the rusticles of shipwreck SH-RD.

From the rusticle samples from shipwreck SH-RE, the total reads generated was 51,156 . The percentage of the unclassified at kingdom level is relatively higher than the total percentage of cyanobacteria and other classes of bacteria, $66.44 \%$. Three classes of cyanobacteria were identified in the shipwreck SH-E Oscillatoriophycideae, Nostocophycideae and Synechococcophycideae, while the class Oscillatoriophycideae showed the most dominant of the three with percentage total read of $14.78 \%$. The total number of reads in rusticle samples in SH-F location is 670,372 . The percentage quality reads are $82.1 \%$. The percentage bacteria identified at kingdom level is $87.55 \%$ and the unclassified at this level is $12.41 \%$. Two clusters of Cyanobacteria were also identified in rusticle samples in shipwreck SH-RF, Oscillatoriphycideae and Nostocophycideae. Again, the class Oscillatoriphycideae makes up the most abundance of the two groups. Of the three wrecks studied the class Oscillatoriphycideae was the most dominant (Figure 3).

Although a universal bacteria primer (27F- 518R) was used for the amplification of the 16S rRNA genes obtained from the rusticle environmental DNA in this study, it is interesting to note that cyanobacteria species dominated other bacterial species found. The species identified are Crocosphaera watsonii, Phorimidium murrayi, Nostoc microscopium, Trichodesium contortum, Oscillatoria coralline, Arthronema africanum, Hydrocoleum lyngbyaceum (Figure 4), (Table 1\& 2). 


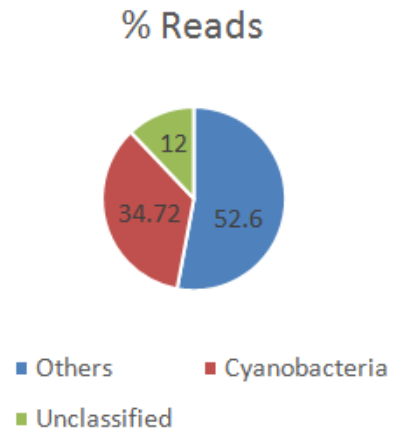

(a) $\mathrm{SH}-\mathrm{RD}$

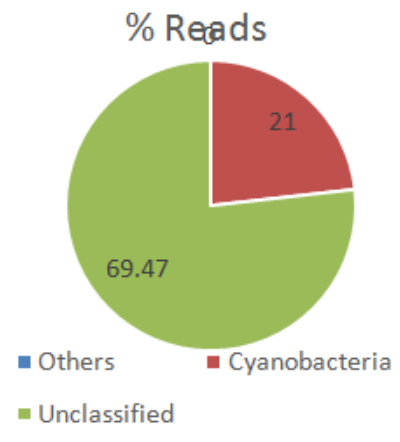

(b) SH-RE
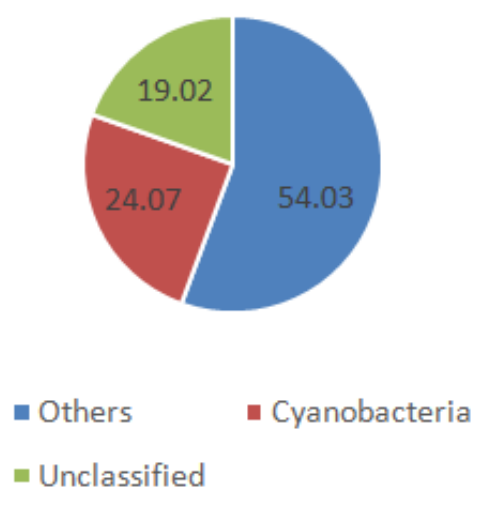

\section{(c) SH-RF}

Figure 3 Percentage read of cyanobacteria in the three Shipwrecks (a-c).

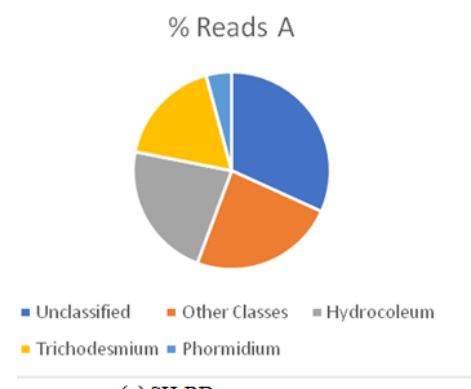

(a) SH-RD
$\%$ Reads B

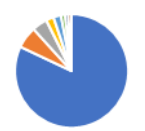

- Unclassified - Crocosphaera m Phormidium $\quad$ = Nostoc

- Trichodesmium $\|$ Hydrocoleum - Oscillatoria - Arthronema (b) SH-RE

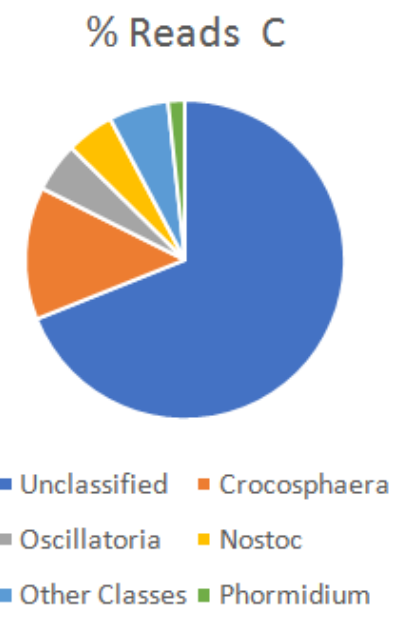

(c) SH-RF

Figure 4 Percentage read of cyanobacteria Genera in the three Shipwrecks $(\mathrm{a}-\mathrm{c})$.
Table I Summary of the bio-concretion growths on the Shipwrecks exterior surfaces

\begin{tabular}{llll}
\hline Shipwrecks & Brown rusticle & Dendritic concretions & Biofilms \\
\hline SH-RD & $* *$ & $* * *$ & $* * *$ \\
SH-RE & $* * *$ & $* * *$ & $* *$ \\
SH-RF & $* * *$ & $* * *$ & $* * *$ \\
\hline
\end{tabular}

Keys: ***, abundance; ${ }^{* *}$, moderate

Table 2 Concentrations of metal on the rusticle samples

\begin{tabular}{llll}
\hline Elements & SH-RD (Mg/Kg) & SH-RE (Mg/Kg) & SH-RF (Mg/Kg) \\
\hline $\mathrm{Fe}$ & 8950 & 9250 & 9050 \\
$\mathrm{Ca}$ & 210 & 385 & 285 \\
$\mathrm{Mn}$ & 162 & 256.5 & 162.5 \\
$\mathrm{Mg}$ & 110 & 170 & 140 \\
\hline
\end{tabular}

Cyanobacteria genera were the most dominant bacteria found on the rusticle samples in all the three shipwreck sites, particularly, Phormidium was detected in the 3 rusticle samples. The SHRD shipwreck site was characterized by a mixed pattern, three Cyanobacteria genera, three Actinobacteria genera and one alphaProteobacteria genus. Hydrocoleum (15.75\%) and Trichodesmium $(12.47 \%)$ being the most dominate genera. While the total genus level taxonomy for SH-RE shipwreck showed a one-directional pattern, only cyanobacteria genera were found, with Crocosphaera $(5.66 \%)$ as the most dominate genus. On the other hand, SH-RF shipwreck had a slightly different pattern, Cyanobacteria was in abundance and also very low number of Alpha-proteobacteria was recorded. The most dominate genus in SH-RF is also the Crocosphaera $(8.12 \%)$. The cyanobacterial genera present in SH-RD and SH-RE are Hydrocoleum, Trichodesmium, and Phormidium. While the genera found common to SH-RE and SH-RF were, Crocosphaera, Oscillatoria, Phormidium and Nostoc. On the other hand, the genus common to both SH-RD and SH-RF was Phormidium.

\section{Discussion}

Shipwrecks are one of the numerous surfaces with distinct physical and chemical properties found submerged in water. They have been referred to as 'hot spot' diversity for organisms ${ }^{11}$ and are known to serve for microbially catalysed, biogeochemically important activities. ${ }^{12}$ Predictably, the nature of its surface plays important role in the microbial adaptation and biogeochemical functioning in marine environments. Surface associated microorganisms play important roles in numerous critical marine processes, including organic matter remineralization nutrient regeneration and element cycling. ${ }^{12}$ Surfaces once submerged in marine water are rapidly colonized ${ }^{13}$ and subsequent biofilm formation follows a sequence of chemical and biological occurrences.

In our study, cyanobacteria were observed as the dominance colonizers of the shipwreck surfaces. The question is why did the cyanobacteria dominate the rusticle samples and what possible roles are they playing on the shipwrecks? From the state of the art, there is little or no information on cyanobacteria diversity of shipwreck ecosystem. The attempted answer on the possible role of cyanobacteria on the shipwreck surface were compared with the presence and activities of cyanobacteria on biogenic surfaces such as rock submerged in water and also on natural reefs. Larouche ${ }^{14}$ 
observed high abundance of cyanobacteria exclusively on rock biofilms, which is in accordance with our findings. In another study by Hullar ${ }^{15}$ cyanobacteria clones comprise the majority (40\%) of the sediments. Charpy et al., ${ }^{6}$ reported that cyanobacteria have always dominated marine environments and been known as reef builders on Earth. In his review, he stated that all limestone surfaces have a layer of boring algae in which cyanobacteria often play a dominant role. This suggested role, played by cyanobacteria was further explained by the study of Walker, ${ }^{16}$ that the boring activity of euendolitic cyanobacteria (living within or penetrating deeply unto stony substances as rocks, and corals) results in biological corrosion and disintegration of carbonate surfaces. This gives an insight into the possible role of cyanobacteria on the shipwreck surface, maybe similar biological corrosion processes and the disintegration of the metal surfaces. This could suggest that cyanobacteria could possibly have a part to play in metal corrosion in shallow water and mostly in brackish water. This fact could explain the predominance of cyanobacteria in our rusticle samples. Indeed, according to Charpy et al., ${ }^{6}$ we can associate the formation of rusticles by bacteria and especially by cyanobacteria as one of their eroding characteristics in shipwrecks. The photosynthetic activity of cyanobacteria, their extracellular polymeric substances, and possibly also the adherent heterotrophic bacteria are responsible for the construction of various carbonate structures and the ability to penetrate shipwreck hull. ${ }^{6}$

Grazing organisms on carbonate surfaces colonized by epi- and endolithic cyanobacteria also produce specific biokarst forms and specific grains that can contribute to near-shore sedimentation, biological corrosion and abrasion altogether constitute bioerosion.

Having established the general roles of cyanobacteria on the shipwreck surface, insight into the specific genera that make up the community can further reveal their individual roles in the shipwreck ecosystem. Phormidium murrayi was the only species common to the three wrecks although in relatively low abundance on the three shipwrecks (2.93\%, 3.78\% and $1.03 \%$ respectively). The presence of Phormidium on the rusticle samples is substantiated with the report from other researchers about the ubiquity of this genus, Phormidium. And that their presence is not surface-specific, that means that Phormidium are not strictly related to a specific lithic substratum. Although, Macedo et al., ${ }^{17}$ portend that this genus prefer siliceous substratum. The genus Phormidium is an endolithic cyanobacteria which has gelatinous sheet that play an important role in adhesion to the substratum. As endolithic organism, they have been reported to penetrate deep down rocks. ${ }^{16}$ This then suggest that, they have potential to penetrate the shipwreck metals. With the activities of the bacteria consortia (sulphate reducing bacteria (SRB), Iron related Bacteria (IRB) and acid producing bacteria (APB)) held together in a biofilm ${ }^{13}$ and the release of metabolic substances that could corrode and form pitting as a result of the $\mathrm{H}_{2} \mathrm{~S}$ released on metal surfaces by the SRB.

There are two genera of cyanobacteria that dominated the rusticle samples, Trichodesmium and Crocosphaera. There was an abundance of Trichodesmium in SH-RD and SH-RE and an abundance of Crocosphaera watsonii in SH-RE and SH-RF.

Four species of Trichodesmium were identified in the rusticle samples; T. erythraeum, T. hildebrandtii, T. tenue and T. contortum. According to Janson et al., ${ }^{18}$ a genetic characterization of Trichodesmium revealed two distinct clades; Clades I and II. There was a good representation of these two clades in the species of Trichodesmium found in our study.
According to Janson et al., ${ }^{18}$ characterisation, Clade I - contains: T. erythraeum $(8.75 \%)$ and T. contortum $(1.04 \%)$ while Clade II-contains: T. tenue $(1.02 \%)$ and T. hildebrandtii (1.08\%). T. erythraeum, T. hildebrandtii and T. tenue predominated the rusticle samples from the Unnamed shipwreck 1 (SH-RD) while T. contortum was observed in rusticle samples from Endurance shipwreck (SH$\mathrm{RE}$ ). The Unnamed shipwreck 2 (SH-RF) had no representation of the Trichodesmium species. In classical grouping based on morphology, T. tenue always was clustered with T. erythraeum. ${ }^{18}$ These two species were noticed clustering together in the same pattern in our study in SH-RD samples. Trichodesmium thrives in stratified, warm water with high light ${ }^{19}$ and this can explain the abundance of Trichodesmium in the rusticle samples, the wrecks are submerged in water though but in shallow water where sunlight could easily reach these phototrophic bacteria.

It has been reported that nutrients such as phosphorus $(\mathrm{P})$ and iron (Fe) affects Trichodesmium growth and nitrogen fixation rates. ${ }^{20}$ The high availability of $\mathrm{Fe}$ in our rusticle could possibly explain the high abundance of cyanobacteria. The rich presence of Trichodesmium among the species of bacteria found under cyanobacteria revealed that the bioavailability of $\mathrm{Fe}$ can encourage the abundance and activity of Trichodesmium in the rusticle samples.

Trichodesmium species often form extensive blooms that are visible from space. Although, Hynes et al., ${ }^{21}$ argued that the presence of Trichodesmium clade I cells in deep region does not necessarily indicate growth under those conditions, but that cells may have been carried there by water current. The low temperature and depth may suggest that clade I has higher tolerance for low light and cold conditions than clade II.

In our study, $T$. erythraeuma member of clade I dominated shipwreck SH-RD which is almost completely submerged in sediments at an abundance level of $8.25 \%$, While members of clade II were low in abundance. This is in agreement with the findings of Hynes, ${ }^{21}$ who observed that clade I was more in colder and deeper areas in pacific than clade II. The clade II members were observed very low in the samples from the Unknown shipwreck I and Endurance shipwreck. $T$. contorum a member of clade I was observed in SH-RE rusticle, this wreck is located where the water is shallow and warmer, and was not completely submerged in the water but the hulls were usually covered when the water tide was high and exposed in low tide.

Our study observed a great diversity of cyanobacteria in the shipwreck ecosystem and much more the diversity that existed within the genus Trichodesmium. The two major clades present in our study have been reported to exist in tropical and subtropical waters. ${ }^{22}$ The ecological role of Trichodesmium is Nitrogen fixation, an ability that enables them to grow successfully where little or no combined nitrogen is available. ${ }^{3}$ Trichodesmium species is a dominant oxygenic marine diazotroph that differs from Crocosphaera in that it fixes both nitrogen and carbon during the day (Inomura et al., 2019). In view of this, Trichodesmium species does not make use of iron conservation strategy to the extent used by Crocosphaera.

Crocospaera watsonii richly dominated two of our shipwrecks, SH-RE (5.62\%) and SH-RF (8.12\%). Crocospaera watsonii belongs to a novel genus of marine unicellular diazotrophic cyanobacteria that occur in marine waters warmer than $24.5^{\circ} \mathrm{C}$. The size, abundance and rapid growth rate of Crocosphaera watsonii indicate that the diazotrophic cyanobacteria is capable of contributing significantly to oceanic carbon and nitrogen budgets in the tropical regions of 
the world's oceans and are predicated to be limited by iron in most marine environments (Inomura et al., 2019). This is consistent with our report, since the abundance of Crocosphaera watsonii could be attributed to the richness of iron on the steel of the shipwreck surface.

Phormidium murrayi, Oscillatoria coralline and Nostoc Microscopium were present in relatively low abundance. Macedo et al. ${ }^{17}$ reported the ubiquity of the genus Phormidium, are commonly reported on cultural heritage and that their presence is not related to a specific lithic substratum. This seems to be in agreement with our findings since this genus was observed on the three shipwrecks. Many genera of Oscillatoria are known to produce wide variety of toxins have also been related to neuro-muscular organ distress as well as external contact irritation both in fresh and marine habitat and can be a threat to marine habitat. Therefore, monitoring of cyanobacteria in marine environments is very important and needed. ${ }^{23}$ All species of Oscillatoria grow in mats on different substrates ranging from (mud, sand bottom, stones and any anthropogenic surface as shipwrecks or any other derelicts) mainly in shallow water habitats.

Could any potential risk exist as cyanobacteria inhabit shipwrecks? From our study, a great deal of cyanobacteria-diversity has been observed on the shipwreck surfaces. These shipwrecks have also been reported as hot spot for marine biodiversity, ${ }^{11}$ as artificial reef it forms an extra habitat for fish ${ }^{24}$ and are also susceptible for the settlement of a wide range of benthic invertebrates. ${ }^{11}$ Zebra Mussels a marine invertebrate that attaches to hard surfaces was reported to have substantially covered the six shipwrecks on Lake Champlain. ${ }^{25}$ The concentration of the Zebra mussel was found around metal fittings and fastenings and also on both the vertical and horizonal surfaces of the wrecks. Interestingly, in our study colonies of Mussels were found in patches on the both horizontal and vertical surfaces of our three shipwrecks although more were found on the vertical surface. The point is this, shipwreck as hot spot for marine diversity (habitat) and also being richly colonized by cyanobacteria, can expose these marine invertebrates to the risk of ingesting toxic cyanobacteria. And if this is possible, these fish and other marine invertebrates that feeds on toxic cyanobacteria could be in turn eaten by man which can pose a high public health risk.

Microcystins, a toxin from cyanobacteria accumulate in marine invertebrates such as mussels (Prepas et al., 1997). In Mussels the highest concentration of microcystin is found in hepatopancreas, although, it is still uncertain whether the levels of microcystin accumulation are sufficient to pose a risk to humans. This may also depend on the levels of consumption. ${ }^{26}$

\section{Conclusion}

A lot of studies have discussed the biodiversity of cyanobacteria on natural habitats. This study attempted to investigate the biodiversity of cyanobacteria on artificial habitat such as shipwreck. These accidental artificial reefs have provided opportunity to evaluate the cyanobacteria species inhabiting shipwreck structures and their possible role on the wreck. This study serves as a baseline data, the first to characterize the cyanobacteria inhabiting shipwrecks. Difference cyanobacteria found on our shipwreck substratum may not necessarily imply high bioreceptivity of the substratum since many other environmental parameters (temperature, presence of water, and sunlight) play an important role in a successful colonization. Cyanobacteria diversity and abundance is likely dependent on the availability of water that allows them form biofilm on any surface. ${ }^{27}$ Future studies should aim at metagenomics characterization of Trichodesmium species in shipwrecks ecosystem, defining the differences among the species and identifying the mechanisms which enables them to coexist. ${ }^{28-35}$

\section{Author contributions}

CGD collected samples, performed experiments, analysed data, prepared figures; GCO, supervised the project and read the paper.

\section{Conflicts of interest}

The authors declare that the research was conducted in the absence of any commercial or financial relationships that could be construed as a potential conflict of interest.

\section{References}

1. Castenholz RW, Garcia-Pichel F. Cyanobacterial responses to UVradiation. In Whitton BA, Potts M (eds) The ecology of cyanobacteria: Their diversity in time and space. Kluwer Academic Publishers: Dordrecht; 2000. 591-611 p.

2. Waterbury J. Little things, matter a lot. Oceanus Magazine: Woods Hole Oceanographic Institution; 2005.

3. Singh H, Khattar SJ, Ahluwalia AS. Cyanobacteria and agricultural crops. VEGETOS. 2014;27(1):37-44.

4. Castenholz RW. Cyanobacteria. Bergey's Manual of Systematics of Archaea and Bacteria; 2015.

5. Pandey VD. Rock-dwelling Cyanobacteria: survival strategies and biodeterioration of monuments. Int J Curr Microbiol Appl Sci. 2013;2(12):519-524.

6. Charpy L, Casareto BE, Langlade MJ, et al. Cyanobacteria in Coral Reef Ecosystems: A Review. Journal of Marine Biology. 2012;2012:259571.

7. Wagner KV. Reef wrecks. Living oceans foundation; 2011.

8. Davis K, Peter MC, Caselle JE. Herbivorous Fish Populations Respond Positively to a Shipwreck Removal and Associated Alteration of Benthic Habitat. Front Mar Sci. 2018;5:406.

9. Youle M. Small things considered: Shipwreck Microbiology. Schaechter; 2011.

10. Cullimore DR, Johnston LA. Microbiology of concretions, sediments and mechanism influencing the preservation of submerged Archeological Artifacts. International Journal of History \& Archaeology. 2008;12:120 132.

11. Mallefet J, Zintzen V, Massin C, et al. Belgian Shipwreck: Hotspots for marine biodiversity (BEWREMABI). Final Scientific Report, Support Plan for Sustainable Development Policy. (SPSDII); 2008.

12. Dang HY, Lovell CR. Microbial Surface Colonization and Biofilm Development in Marine Environments. Microbiology and Molecular Biology Review. 2016;80(1):91.

13. Held NA, Webb EA, Mcllvin MM, et al. Co-occurrence of Fe and P stress in natural populations of the marine diazotroph Trichodesmium. Biogeeosciences. 2020;17(9):2537-2551.

14. Larouche JR, Bowden WB, Giordano R, et al. Microbial biogeography of arctic streams: exploring influences of lithology and habitat. Front Microbiol. 2012;3:309.

15. Hullar M, Kaplan LA, Stahl DA. Recurring seasonal dynamics of microbial communities in stream habitats. Appl Environ Microbiol. 2006;72(1):713722.

16. Walker JJ, Spear JR, Pace NR. Geobiology of Microbial endolithic community in the Yellowstone geothermal environment. Nature. 2005;434:1011-1014. 
17. Macedo MF, Miller AZ, Dionisio A, et al. Biodiversity of cyanobacteria and green algae on monuments in the Mediterranean Basin: an overview. Microbiology. 2009;155(11):3476-3490.

18. Janson S, Bergman B, Carpenter EJ, et al. Genetic analysis of natural populations of the marine diazotrophic cyanobacterium Trichodesmium. FEMS Microbiol Ecol. 1999;30(1):5765.

19. Capone DG, Burns JA, Montoya JP, et al. Nitrogen fixation by Trichodesmium spp.: An important source of new nitrogen to the tropical and subtropical North Atlantic Ocean. Global Biogeochemical Cycles. 2005;19(2):1-17.

20. Moore CM, Mills MM, Achterberg EP, et al. Large-scale distribution of Atlantic nitrogen fixation controlled by iron availability. Nature Geoscience. 2009;2:867-871.

21. Hynes AM. Diversity of the marine Cyanobacterium Trichodesmium: characterization of the Woods Hole culture collection and quantification of field populations. MIT/WHOI Joint Program PhD thesis, Cambridge; 2009.

22. Bergman B, Sandh G, Lin S, et al. Trichodesmium-a widespread marine cyanobacterium with unusual nitrogen fixation properties. FEMS Microbiology Reviews. 2013;37(3):286-302.

23. Cronberg G, Carpenter EJ, Carmichael WW. Taxonomy of harmful cyanobacteria. In: Hallegraeff GM, Anderson DM, Cembella AD (eds.), Manual on Harmful Marine Microalgae. Unesco Publishing; 2003. 523$562 \mathrm{p}$.

24. Jensen A. Artificial reefs of Europe: perspective and future. ICES Journal of Marine Science: Journal du Conseil. 2002;59:3-13.

25. Watzin CC, Cohn AB, Emerson BP. Zebra Mussels, Shipwrecks and the Environment. Final Report: University of Vermont; 2001.

26. Chorous I, Bartram J. Toxic Cyanobacteria in Water: A guide to their public health consequences, monitoring and management. E \& FN Spon an imprint of Routledge St Edmundsbury Press: Bury St Edmunds, Suffolk. Great Britain; 1999. 400 p.
27. Gorbushina AA. Life on the rocks. Environ Microbiol. 2007;9(7):16131631.

28. Crisp CA, Gaylarde CC. Cyanobacteria and biodeterioration of cultural heritage: a review. Microb Ecol. 2005;49:1-9.

29. Fernández A, Graña R, Mouriño-Carballido B, et al. Community N2 fixation and Trichodesmium spp. abundance along longitudinal gradients in the eastern subtropical North Atlantic. ICES Journal of Marine Science. 2013;70(1):223-231.

30. Fowler AM, Booth DJ. How well do sunken vessels approximate fish assemblages on coral reefs? Conservation implications of vessel-reef deployments. Marine biology. 2012;159:2787-2796.

31. Jimenez C, Andreou V, Evriviadou M, et al. Epibenthic communities associated with unintentional artificial reefs (modern shipwrecks) under contrasting regimes of nutrients in the Levantine Sea (Cyprus and Lebanon) PLoS One. 2017;12(8):e0182486.

32. Jimenez C, Hadjioannou L, Petrou A, et al. Fouling communities of two accidental artificial reefs (modern shipwrecks) in Cyprus (Levantine Sea). Water. 2017;9(1):11.

33. Tripp HJ, Bench SR, Turk KA, et al. Metabolic streamlining in an open $\square$ ocean nitrogen-fixing cyanobacterium. Nature. 2010;464(7285):90-94.

34. Wagner D. The biology and ecology of Hawaiian black corals (Cnidaria: Anthozoa: Hexacorallia: Antipatharia). Ph.D Thesis Oceanography (Marine Biology); 2011.

35. Zintzen V, Massin CL, Mallefet J. Unplanned artificial reefs in the Southern Bight of the North Sea: Shipwrecks as new habitats for epifaunal communities. Proceedings of the 40th European Marine Biology Symposium: Vienna, Austria; 2005. 77 p. 